$17^{\text {th }}$ International Congress of Metrology, 04005 (2015)

DOI: $10.1051 /$ metrology/201504005

(C) Owned by the authors, published by EDP Sciences, 2015

\title{
Dealing with measurement uncertainties in building acoustics
}

\author{
Reine Johansson ${ }^{1}$, María Machimbarrena ${ }^{2}$, Carolina Rodrigues A. Monteiro ${ }^{2}$, Stefano Pedersoli ${ }^{2}$ and Sean Smith ${ }^{3}$ \\ ${ }^{1}$ Swedish Metrology and Quality AB, Dragspelsgatan 21, 50472 Borås, Sweden \\ ${ }^{2}$ Universidad de Valladolid-Applied Physics Department; Avenida de Salamanca s/n, 47014 Valladolid, Spain \\ ${ }^{3}$ Edinburgh Napier University - Institute for Sustainable Construction; Colinton Rd 42, EH10 5BT Edinburgh, Scotland, UK
}

\begin{abstract}
Résumé. L'acoustique du bâtiment est un domaine où les incertitudes ont traditionnellement été signalés comme indiqué par une norme existante, ou non déclarés du tout. Dans un monde où la performance acoustique des éléments de construction (mesurée dans des laboratoires accrédités) et la performance acoustique des solutions constructives (mesurées sur le terrain) doivent être testés et souvent jugés pour se conformer à une exigence, il est recommandé d'effectuer des calculs d'incertitude détaillés. La norme existante "ISO 12999-1: 2014 Détermination et application des incertitudes de mesure dans l'acoustique des bâtiments - Partie 1: Isolation acoustique." comprend des valeurs d'incertitude générales pour mesurandes typiques tels que l'isolation au bruit aérien et d'impact sonore dans différentes situations de mesure, à la fois pour les bandes de tiers d'octave et les valeurs uniques correspondantes. Cet article soutient l'idée de faire des calculs individuels d'incertitude non seulement pour les mesures d'isolation acoustique, mais pour toute mesure en acoustique du bâtiment. Une collection de ces calculs sont présentés pour soutenir la thèse, montrant que ce calcul de l'incertitude individuelle devient plus important lorsque les valeurs uniques sont considérées.
\end{abstract}

\begin{abstract}
Building acoustics is a field where uncertainties have traditionally been reported as stated by an existing standard, or not reported at all. In a world where acoustic performance of building elements (measured in accredited laboratories) and acoustic performance of constructive solutions (measured in the field) must be tested and often judged to comply with a requirement, it is recommended to perform detailed uncertainty calculations. The existing standard "ISO 12999-1:2014 Determination and application of measurement uncertainties in building acoustics - Part 1: Sound insulation" includes general uncertainty values for typical measurands such as airborne and impact sound insulation under different measurement situations, both for third octave bands and single number quantities. This paper supports the idea of making individual uncertainty calculations not only for sound insulation measurements but for any acoustic measurement in building acoustics. A collection of such calculations are shown to support the thesis, showing that this individual uncertainty calculation becomes more important when single number quantities are considered.
\end{abstract}

\section{Introduction}

The measurement of sound insulation in buildings and of building products is a continuously changing field. There are standards relating to laboratory sound insulation measurements ISO 10140 [1] and standards relating to "in situ" or non-laboratory [2-4] sound insulation measurements, some of these being under final draft stage.

Over and above the previous mentioned standards, the corresponding standard dealing with application of measurement uncertainties in building acoustics, has been revised and a new standard ISO 12999-1 [5] has recently been approved. This includes general uncertainty values for typical measurands such as airborne and impact sound insulation under different measurement situations, both for $1 / 3$ octave bands and single number quantities. The uncertainty values reported in the standard are based on a large set of interlaboratory tests as described in [6]. These values shall be used to determine whether a building complies or not with the corresponding regulatory performance requirements. In some countries court proceedings might be implemented depending if requirements are fulfilled or not, and such legal arguments are likely to take uncertainties into account.

There has been much research in this field over recent years. According to some authors [7, 8], it is not possible to follow a GUM [9] approach to determine uncertainties of sound insulation measurements, or it seems reasonable to keep the idea of reproducibility and repeatability

\footnotetext{
${ }^{a}$ Corresponding author: reine.at.work@gmail.com
} 
concepts as used in ISO 12999-1 for building acoustics measurements [10]. One of the claimed problematic aspects $[7,8]$ is that some quantities, like reverberation time and sound pressure levels, are not directly measured. They are derived and often determined by integrating over a field region, which implies some underlying assumptions. When underlying assumptions are not fully met it is difficult to obtain a full mathematical model including all relevant effects and this is the main reason why uncertainty of sound insulation measurements has not yet been determined using a GUM approach. As a consequence, some parts consider that the uncertainty of a sound insulation measurement shall be stated as the uncertainty of the corresponding measurement method, based on the results of interlaboratory measurements described in ISO 12999-1 and no individual uncertainty calculation is performed. However, this leads to some problems such as the measurement uncertainty contribution from the object is not properly included in the results.

\section{Reasons to perform uncertainty calculations for building acoustics measurements}

The purpose of a measurement is to determine the value of a quantity of interest, the measurand. The measurand can for example be the sound pressure level, sound power level, sound reduction index or a single number quantity like $\mathrm{D}_{\mathrm{nT}, \mathrm{A}}$. In reality this usually means to sample one value out of a universe of possible values, since in general, when one repeats a measurement, one will obtain different answers. This observed variability in the results of repeated measurements arises because the influence parameters that can affect the measurement result are changing. In general, there are many influence parameters affecting a measurement result. Although it is impossible to identify all of them, the most significant can normally be identified and the magnitude of their effects on the measurement result can be estimated. Moreover, the way they influence the measurement result can, in many cases, be mathematically modelled. These models can be retrieved theoretically, empirically or as a mixture between these two methods.

There are many ways to estimate measurement uncertainties. However, accreditation bodies that are members of the International Laboratory Accreditation Cooperation Mutual Recognition Arrangement (ILAC MRA) have agreed on requiring their accredited calibration laboratories to determine uncertainties in compliance with ISO 17025 [11], GUM, including its supplements, and/or ISO Guide 35 [12]. Also for test laboratories GUM is a basic document for estimating uncertainties [13], although some exceptions exist for test laboratories, e.g. when the process for evaluation of the measurement uncertainty is included in a test standard. ILAC G17 [13] however states that these standards should be reviewed and revised accordingly by the standards organisation. This means that any new standard that aims at being used within the ILAC MRA should, whenever it is possible, use GUM, or corresponding documents from the accreditation bodies, as basic documents when estimations of measurement uncertainties are made within the standard.

Some technical areas by tradition only work with repeatability and reproducibility while trying to attribute a value describing the quality of the measurement result. This may be satisfactory as long as the reproducibility gives the major contribution to the total measurement uncertainty, and the other measurement uncertainty components give negligible contributions. Nevertheless, to fulfil the requirements in ISO 17025 it is important to investigate and document other possible uncertainty components that may influence the measurement results.

Traditionally in building acoustics, estimations of method uncertainties have been performed according to ISO $5725[14,15]$. The two approaches in ISO 5725 and in GUM are different. ISO 5725 considers the measurement system like a "black box" and has a topdown approach where one does not need to have detailed knowledge about how different parameters affect the measurement results, whereas GUM has a bottom-up approach which demands a model for undertaking a measurement uncertainty analysis.

A recurrent argument for not using GUM within building acoustics is that no complete model exists for the measurands. However, although some kind of model is needed by GUM, there is no requirement that it shall be complete. In fact the word model itself implies that it is not a perfect description of the real world. In GUM it is also pointed out that one uncertainty component that always shall be considered is the uncertainty introduced by the model used in the measurement uncertainty analysis.

When considering single number quantity uncertainty, experimental data $[6,7]$ shows that correlations exist between different $1 / 3$ octave bands, but it is not possible to identify exactly how big they are in all measurements. Correlations are often possible to investigate by experiments and calculations, but if for some reason, it is impossible to retrieve correlations this way, GUM is permissive and will allow estimations based on experience. If the single number quantity uncertainty is determined considering full positive correlation between $1 / 3$ octave bands, the result is higher than the one obtained if no correlation between $1 / 3$ octave bands is considered. Assuming full correlation will likely lead to an overestimated uncertainty contribution due to correlation. Under the GUM approach, when estimating the measurement uncertainty, if there is no knowledge at all, the normal procedure is to make a conservative estimation until more knowledge is obtained. This means that one rather overestimate than underestimate the uncertainty contributions from a specific parameter. In the case of correlations, it means that a correlation coefficient equal to 1 should be used until more experience is acquired to make a better judgment. However, if experience indicates that the estimated correlation coefficient is not bigger than for example 0.8 , then, this is the number to use in the measurement uncertainty calculations. 
The former problem for GUM, with strongly nonlinear systems, has been solved by introducing a GUM Supplement [9]. This is where Monte Carlo simulations can be used for propagating probability density functions through the models, to give an estimate of the measurement uncertainty. GUM also gives examples of how to use higher-order terms in the Taylor expansion series to handle non-linear systems.

The approach for dealing with sound insulation measurements described in ISO 12999-1, where no individual uncertainty calculation is performed is somehow contradictory with ISO 17025 and some accreditation procedures, as mentioned before. In some countries, e.g. Spain and Portugal, the accreditation bodies demand from the test laboratories measurement uncertainty budgets in accordance to GUM or EA-4/02 [16]. As different laboratories have different environments, personnel, equipment, test objects etc. and are spread all over the world, it often makes sense to give different measurement uncertainties even though the method used is the same. This is why making individual uncertainty calculations also in the field of building acoustics is encouraged in this paper.

\section{Objective}

The main objective of this paper is to encourage laboratories, consultants and scientists working in the field of building acoustics to perform uncertainty estimations following GUM's recommendations.

This recommendation is not only for sound insulation measurements, but for any acoustic measurement, especially so if performed by an accredited laboratory, for example sound absorption.

In a previous paper [17] a preliminary procedure on how to perform these estimations for in situ airborne sound insulation measurements has been described and the procedure has been applied to a large data set. Since this paper was published in an Acoustic Journal and it was considered to be of interest of the metrology community, it was decided to write a reduced and adapted version for a metrology congress and thus increase the chances for discussion among experts in the field.

\section{Results from a case study}

The most common parameter used to evaluate the airborne sound insulation of a building (thus, in situ measurement) is the standardized level difference, $\mathrm{D}_{\mathrm{nT}}$

$$
D_{n T}=L_{1}-L_{2}+10 \log \frac{T}{T_{0}} \quad \text { in } \mathrm{dB}
$$

where $L_{1}$ is the energy-average sound pressure level in the source room, $\mathrm{L}_{2}$ is the energy-average sound pressure level in the receiving room, $\mathrm{T}$ is the reverberation time in the receiving room and $\mathrm{T}_{0}$ is the reference reverberation time which for dwellings is $T_{0}=0.5 \mathrm{~s}$. This is a frequency dependent magnitude and is usually measured in $1 / 3$ octave bands going from $100 \mathrm{~Hz}$ to $5000 \mathrm{~Hz}$, although this may vary.
This frequency dependent result can be converted into a single number quantity (SNQ) following different procedures $[19,20]$, and it is the SNQ which must be reported in order to verify compliance with a Building Code requirement.

A similar procedure is followed for laboratory measurements when testing products such as windows, doors or full constructive solutions.

In this case study a large data base of measured $\mathrm{D}_{\mathrm{nT}}$ of four different types of walls was available (1102 measurements). All walls were constructed in the UK in compliance with the relevant Robust Details [20] specifications. Testing according to [21] and on-site inspections were carried out to ensure compliance with the construction system by workmanship and with Building Regulations. The measurements where performed by Robust Details inspectors. Details of the data set can be found in [17].

The suggested uncertainty determination procedure can be summarized in the following equation

$$
u\left(D_{n T_{i}}\right)=\sqrt{\begin{array}{c}
{\left[u_{\text {rep }}\left(L_{1}\right) \cdot c_{L_{1}}\right]^{2}+\left[u_{\text {rep }}\left(L_{2}\right) \cdot c_{L_{2}}\right]^{2}+\ldots} \\
\ldots+\left[u_{\text {rep }}\left(L_{\mathrm{b}}\right) \cdot c_{b}\right]^{2}+\left[u(T) \cdot c_{T}\right]^{2}+\left[u_{\text {ins }} \cdot c_{\text {ins }}\right]^{2}
\end{array}}
$$

where the standard uncertainty for each input estimate can be determined including the experimental standard deviation and other possible uncertainty contributions such as the instrument uncertainty, background noise.

Figure 1 shows a random selection out of the 300 calculated uncertainty curves obtained. As it can be seen, the spread in the values is significant and supports the need of making detailed uncertainty calculations when performing sound insulation tests. This spread is more evident at low frequencies than in the medium-high frequency range, although a considerable spread is also found in the higher end of the frequency range.

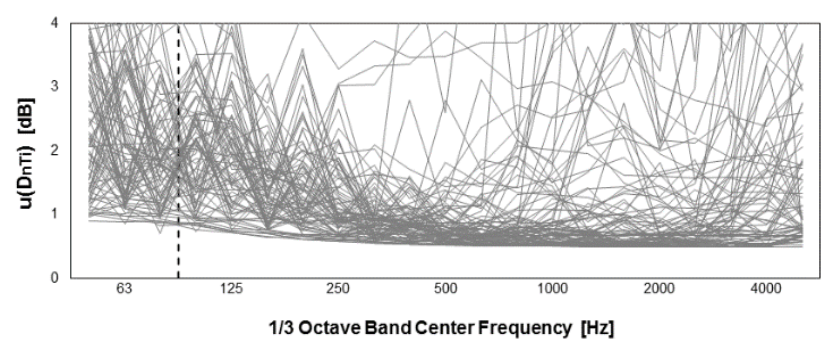

Figure 1: Spread of individual values $u\left(D_{n T_{i}}\right)$ for full data set

As mentioned previously, when verifying requirement compliance, one shall use a single number quantity. In this case the $\mathrm{D}_{\mathrm{nT}, \mathrm{A}}$ is used.

$$
D_{n T, A}=-10 \log \sum_{i=1}^{n} 10^{\left(L_{A r, i}-D_{n T, i}\right)} / 10
$$

where $L_{A r}$ is a reference spectrum and " $i$ " stands for the corresponding third octave band both for the reference spectrum and the standardised level difference.

To calculate $\mathrm{D}_{\mathrm{nT}, \mathrm{A}}$ uncertainty one can assume full positive correlation between the $1 / 3$ octave band uncertainties input. The assumption of full correlation 
will likely overestimate the standard uncertainty, but one does not want to risk underestimating the uncertainty so this is the assumption that has been made. For this calculation the previously obtained individual uncertainties data curves have been used as input. This can be done using different frequency ranges (i.e. starting at $50 \mathrm{~Hz}$ or $100 \mathrm{~Hz}$ and ending at $5000 \mathrm{~Hz}$ ). For example for $\mathrm{D}_{\mathrm{nTA}(50-5000)}$ :

$$
u\left(D_{n T A 50-5000}\right)=\sum_{i=1}^{N}\left(\frac{10^{\left(L_{i}-D_{n T_{i}}\right) / 10}}{\sum_{k} 10^{\left(L_{k}-D_{n T_{k}}\right) / 10}}\right) \cdot u\left(D_{n T_{i}}\right)
$$

Due to the assumption of full correlation, formula (4) consists of a linear addition instead of the square root of a sum of squares.

Figure 2 represents, for the full data set, the spread of the uncertainty values for the single number quantity $\mathrm{D}_{\mathrm{nTA}}$ and the corresponding uncertainty average, using two different frequency ranges. One can from the data state with a confidence level higher than $99,9 \%$ that $\overline{u\left(D_{n T A}\right)_{50-5000}}$ is bigger than $\overline{u\left(D_{n T A}\right)_{100-5000}}$.

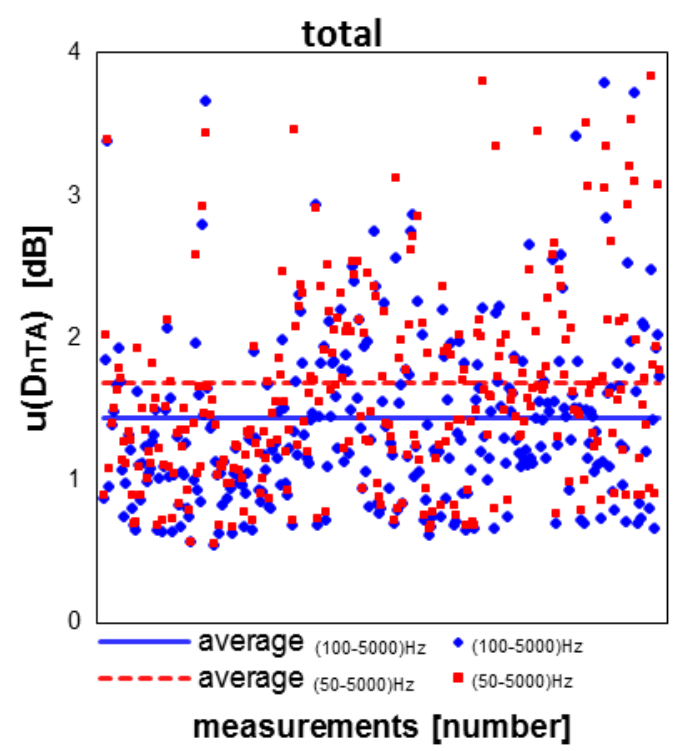

Figure 2: Spread of $u\left(D_{n T A}\right)$ values and average $\overline{u\left(D_{n T A}\right)}$ for the full dataset

In calibration and test certificates issued by accredited laboratories the expanded uncertainty for a measurement value is normally given with the coverage factor $\mathrm{k}=2$, which for a Gaussian distribution corresponds to a coverage probability of approximately $95 \%$. In this case study the coverage factor selected was $\mathrm{k}=1.7$, defining an interval having a level of confidence of approximately $95 \%$ for single sided tests used when verifying compliance, although a different coverage factor could have been chosen. For example for $\mathrm{D}_{\mathrm{nTA}}(50-5000)$ :

$$
U\left(D_{n T A(50-5000)}\right)=k \cdot u\left(D_{n T A(50-5000)}\right)
$$

Table 1 shows the calculated average expanded uncertainty of the single number quantity $\mathrm{D}_{\mathrm{nTA}}$ for each type of wall used in this case study. It has been assumed that $\mathrm{D}_{\mathrm{nTA}}$ has a Gaussian distribution, which could be discussed [22, 23], and a coverage factor $\mathrm{k}=1.7$ which corresponds to approximately $95 \%$ confidence level for a cumulative distribution (single sided) has been used.

It shall be mentioned that the degrees of freedom or other possible measurement uncertainty contributions have not been considered when calculating $U\left(D_{n T A}\right)$.

Although average values are shown, in almost $10 \%$ of the case studies presented $u\left(D_{n T A}\right)_{50-5000}>3 \mathrm{~dB}$ and the corresponding expanded uncertainty for the reported $\mathrm{D}_{\mathrm{nTA}(50-5000)}$ was found to be $\mathrm{U}>5.1 \mathrm{~dB}$. This can make a significant difference when trying to fulfil a performance requirement.

The results of this study confirm that expanded uncertainties vary considerably for different types of walls and/or different frequency ranges and thus should be determined individually for each field measurement.

Table 1: Calculated average expanded uncertainty of the single number quantity $\mathrm{D}_{\mathrm{nTA}}$ for different types of walls.

\begin{tabular}{|c|c|c|}
\hline (average values) & & \\
\cline { 1 - 2 } Type of wall & $U\left(D_{n T A}\right)_{50-5000}$ & $U\left(D_{n T A}\right)_{100-5000}$ \\
\hline HWA_75 & 2.41 & 2.18 \\
\hline HWA_100 & 2.35 & 2.16 \\
\hline HWB_75 & 3.07 & 2.65 \\
\hline HWB_100 & 2.50 & 2.25 \\
\hline LWA_50 & 3.61 & 2.79 \\
\hline LWB_50 & 3.22 & 2.60 \\
\hline
\end{tabular}

\section{Conclusions}

There are high demands on a building's performance concerning energy saving, low carbon, safety and acoustic performance. Future directions may require new buildings to be graded according to their acoustic "quality" [24]. It is of high importance to adequately assess and report such performance including the corresponding uncertainty.

From the literature review and the results of the case study, it is concluded that it is possible to make individual uncertainty estimations for airborne sound insulation.

Moreover the big variation of uncertainties between walls and/or different frequency ranges implies that individual measurement uncertainty estimations should be performed to not underestimate the measurement uncertainty.

This thesis can be extended to impact and façade sound insulation in a similar way. There is not a unique procedure and most likely some type of guidelines should be included in the next version of ISO 12999-1, if only as an alternative to interlaboratory based uncertainties. If the standard is to be used in relation to accredited measurement services, it should be revised to follow the basic documents mentioned in ILAC's guidelines.

\section{References}


[1] ISO 10140- Acoustics -- Laboratory measurement of sound insulation of building elements - parts 1 to 5 . 2010 .

ISO 16283-1:2014 Acoustics -- Field measurement of sound insulation in buildings and of building elements -- Part 1: Airborne sound insulation. International Organization for Standardization; 2014.

[3] ISO/FDIS 16283-2: Acoustics - Field measurement of sound insulation in buildings and of building elements - Part 2: Impact sound insulation. 2015.

[4] ISO/FDIS 16283-3: Acoustics - Field measurement of sound insulation in buildings and of building elements - Part 3: Façade sound insulation. 2015.

[5] ISO 12999-1 Acoustics -- Determination and application of measurement uncertainties in building acoustics -- Part 1: Sound insulation. Geneva, Switzerland: International Organization for Standardization; 2014.

[6] Wittstock V. Determination of Measurement Uncertainties in Building Acoustics by Interlaboratory Tests. Part 1: Airborne Sound Insulation. Acta Acust United with Acust 2015;101:88-98.

[7] Wittstock V. On the uncertainty of single-number quantities for rating airborne sound insulation. Acta Acust United With Acust 2007;93:375-86.

[8] Wittstock V, Bethke C. On the uncertainty of sound pressure levels determined by third-octave band analyzers in a hemianechoic room. Forum Acusticum, Budapest,Hungary: 2005.

[9] JCGM 101:2008 Evaluation of measurement data Supplement 1 to the "Guide to the expression of uncertainty in measurement" - Propagation of distributions using a Monte Carlo method. vol. JCGM 101:2. Joint Committee For Guides In Metrology; 2008.

[10] Luque P, Fernández D, Colina C de la, Simón F. Convergencia de la repetibilidad de ensayos de aislamiento a ruido aéreo in situ. Tec. 2005, Sociedad Española de Acústica; 2005.

[11] ISO 17025:2005 General requirements for the competence of testing and calibration laboratories. International Laboratory Accreditation Cooperation; 2005.

[12] ILAC P14:01/2013 ILAC Policy for Uncertainty in Calibration. International Laboratory Accreditation Cooperation; 2013.

[13] ILAC-G17:2002 Introducing the Concept of Uncertainty of Measurement in Testing in Association with the Application of the Standard ISO/IEC 17025. International Laboratory Accreditation Cooperation; 2002.
[14] ISO 5725-1:1994 Accuracy (trueness and precision) of measurement methods and results -- Part 1: General principles and definitions. Geneva, Switzerland: International Organization for Standardization; 1994.

[15] ISO 5725-2:1994 Accuracy (trueness and precision) of measurement methods and results -- Part 2: Basic method for the determination of repeatability and reproducibility of a standard measurement method. Geneva, Switzerland: International Organization for Standardization; 1994.

[16] EA-4/02 M:2013 -- Evaluation of the Uncertainty of Measurement in Calibration. European co-operation for Accreditation; 2013.

[17] Machimbarrena M, Monteiro CRA, Pedersoli S, Johansson R, Smith S. Uncertainty determination of in situ airborne sound insulation measurements. Appl Acoust 2015;89:199-210.

[18] ISO 717- Acoustics -- Rating of sound insulation in buildings and of building elements -- Part 1: Airborne sound insulation- Part 2: Impact sound insulation. 2013.

[19] Mondaca C, Machimbarrena M, Monteiro CRA. Comparison of some global indices to adequately assess airborne sound insulation. Euronoise 2012, 2012 .

[20] Robust Details Ltd. Robust details handbook. Part E: Resistance to the passage of sound. 3rd ed. Milton Keynes, UK: 2013.

[21] ISO 140-4:1998 Acoustics -- Measurement of sound insulation in buildings and of building elements -- Part 4: Field measurements of airborne sound insulation between rooms. Geneva, Switzerland: International Organization for Standardization; 1998.

[22] Mahn J, Pearse J. The Uncertainty of the Proposed Single Number Ratings for Airborne Sound Insulation. Build Acoust 2012;19:145-72.

[23] Mondaca C, Monteiro CRA, Machimbarrena M Análisis de la variabilidad e incertidumbre de medidas "in situ" del aislameinto acústico a ruido aéreo de paredes pesadas. VIII Congr. Iberoam. Acústica, Evora: 2012.

[24] COST TU0901. Building acoustics throughout Europe Volume 1: Towards a common framework in building acoustics throughout Europe. DiScript Preimpresion, S. L.; 2014. 